\title{
Putting the spark into physical science and algebra
}

\section{Bruce Pill, Andre Dagenais}

Bruce Pill, Andre Dagenais, "Putting the spark into physical science and algebra," Proc. SPIE 9665, Tenth International Topical Meeting on Education and Training in Optics and Photonics, 966520 (3 June 2007); doi: $10.1117 / 12.2207917$

SDIE Event: Tenth International Topical Meeting on Education and Training in Optics and Photonics, 2007, Ottawa, Ontario, Canada 


\section{Putting the "Spark" into Physical Science and Algebra \\ Bruce Pill and Andre Dagenais, Sanford School \\ pillb@sanfordschool.org and dagenaisa@sanfordschool.org}

The presenters will describe a number of laboratory activities developed in collaboration with the Department of Electrical Engineering at the University of Delaware as part of their outreach program to help make math and science more authentic on the pre-college level. Lessons relating to electrical topics are often abstract and appropriate only for advanced students in math and science. We have devised lessons that rely on simple equipment. They promote skills that are included in National and State Standards. They emphasize the connections between math and science; they are appropriate for an algebra course, a physical science course, a PhysicsFirst course or a traditional physics course. Students benefit from seeing that what they learn in math and science courses can lead to cutting-edge work in areas such as passive wave imaging, photonics, wireless communication and high performance computing. The collaboration has been meaningful because it has motivated us to tailor our lessons to reflect what is happening in the research lab of our local university. Written materials for use in teacher training workshops will also be available.

Funded by NSF Research Experience for Teachers(RET \#0322633) program under the direction of Dr. Dennis Prather, University of Delaware Electrical Engineering 